\title{
Studi Implementasi Akad Rahn (Gadai Syariah) Pada Lembaga Keuangan Syariah
}

\author{
Surepno \\ Institut Agama Islam Negeri Kudus \\ surepno@iainkudus.ac.id
}

\begin{abstract}
The development of sharia-based products is increasingly prevalent in Indonesia, including pawnshops. Perum pawnshops issued sharia-based products called sharia pawnshops. Basically, sharia-based products have such characteristics, do not collect interest in various forms due to usury, determine money as a medium of exchange not as a commodity traded, and do business to obtain compensation for services and or profit sharing.

This research includes the type of literature study by looking for theoretical references that are relevant to cases or problems found. Theoretical references obtained by means of literature study research and then used as the basic foundation and main tools for analyzing data. The type of data used by the authors in this study is secondary data obtained from journals, books, documentation and the internet. The data that has been obtained is then analyzed using descriptive analysis method

Islamic Pawnshop or known by the term rahn, in its operation using the Fee Based Income (FBI) or Mudharabah (profit sharing) method. Because customers in using UP (UP) have different objectives, for example for consumption, paying school fees or additional working capital, the use of the Mudharabah method has not been properly used. Therefore, pawnshops use the Fee Based Income (FBI) method.
\end{abstract}

Keywords: contract, rahn, Fee Based Income, Islamic financial institutions

\begin{abstract}
Abstrak
Perkembangan produk-produk berbasis syariah kian marak di Indonesia, tidak terkecuali pegadaian. Perum pegadaian mengeluarkan produk berbasis syariah yang disebut dengan pegadaian syariah. Pada dasarnya, produk-produk berbasis syariah memiliki karakteristik seperti, tidak memungut bunga dalam berbagai bentuk karena riba, menetapkan uang sebagai alat tukar bukan sebagai komoditas yang diperdagangkan, dan melakukan bisnis untuk memperoleh imbalan atas jasa dan atau bagi hasil.

Penelitian ini termasuk jenis penelitian studi literatur dengan mencari referensi teori yang relevan dengan kasus atau permasalahan yang ditemukan. Referensi teori yang diperoleh dengan jalan penelitian studi literatur dan kemudian dijadikan fondasi dasar dan alat utama untuk menganalisis data. Jenis data yang digunakan oleh penulis dalam penelitian ini adalah data sekunder yang diperoleh dari jurnal, buku, dokumentasi dan internet. Data-data yang sudah diperoleh kemudian dianalisis dengan menggunakan metode analisis deskriptif Pegadaian syariah atau dikenal dengan istilah rahn, dalam pengoperasiannya menggunakan metode Fee Based Income (FBI) atau Mudharabah (bagi hasil). Karena nasabah dalam mempergunakan marhum bih (UP) mempunyai tujuan yang
\end{abstract}


berbeda-beda misalnya untuk konsumsi, membayar uang sekolah atau tambahan modal kerja, penggunaan metode Mudharabah belum tepat pemakaiannya. Oleh karenanya, pegadaian menggunakan metode Fee Based Income (FBI).

Kata kunci: akad, rahn, Fee Based Income, lembaga keuangan syariah.

\section{PENDAHULUAN}

Syari'at Islam memerintahkan umatnya agar saling tolongmenolong dalam segala hal, salah satunya dapat dilakukan dengan cara pemberian atau pinjaman. Dalam bentuk pinjaman hukum Islam menjaga kepentingan kreditur atau orang yang memberikan pinjaman agar jangan sampai ia dirugikan. Oleh sebab itu, pihak kreditur diperbolehkan meminta barang kepada debitur sebagai jaminan atas pinjaman yang telah diberikan kepadanya.

Gadai-menggadai sudah merupakan kebiasaan sejak zaman dahulu kala dan sudah dikenal dalam adat kebiasaan. Gadai sendiri telah ada sejak zaman Rasulullah Saw. dan Rasulullah sendiri pun telah mempraktikkannya.

Tidak hanya ketika zaman Rasulullah saja, tetapi gadai juga masih berlaku hingga sekarang. Terbukti dengan banyaknya lembaga-lembaga yang menaungi masalah dalam gadai itu sendiri, seperti Pegadaian dan sekarang muncul pula Pegadaian Syariáh. Di dalam Islam, pegadaian itu tidak dilarang, namun harus sesuai dengan Syariát Islam, seperti tidak memungut bunga dalam praktik yang dijalankan.

Terbitnya PP 10 tanggal 1 April 1990 dapat dikatakan sebagai tonggak awal kebangkitan Pegadaian. PP10 menegaskan misi yang harus diemban oleh pegadaian untuk mencegah praktik riba. Misi ini tidak berubah hingga terbitnya PP103/2000 yang dijadikan sebagai landasan kegiatan usaha Perum Pegadaian sampai sekarang. Banyak pihak berpendapat bahwa operasionalisasi Pegadaian pra-Fatwa MUI tanggal 16 Desember 2003 tentang Bunga Bank, telah sesuai dengan konsep syariah meskipun harus diakui belakangan bahwa terdapat beberapa aspek yang menepis anggapan itu. Berkat Rahmat Allah SWT dan setelah melalui kajian panjang, akhirya disusunlah suatu konsep pendirian unit Layanan Gadai Syariah sebagai langkah awal pembentukan divisi khusus yang menangani kegiatan usaha syariah (Khaerul Umam, 2013: 356-357)

\section{KAJIAN LITERATUR}

\section{Akad Rahn}

Gadai dalam bahasa Arab disebut rahn, yang berarti tetap, kekal, dan jaminan. Secara syara, rahn adalah menyandera sejumlah harta yang diserahkan sebagai jaminan secara hak, tetapi dapat diambil kembali sebagai tebusan. 
Gadai merupakan salah satu kategori dari perjanjian utang piutang, yang mana untuk suatu kepercayaan dari orang yang berpiutang, maka orang yang berutang menggadaikan barangnya sebagai jaminan terhadap utangnya itu. Barang jaminan tetap milik orang yang menggadaikan (orang yang berhutang) tetapi dikuasai oleh penerima gadai (yang berpiutang). Konsep tersebut dalam fiqh Islam dikenal dengan istilah rahn atau gadai (Muhammad Firdaus, 2005: 68)

Akad rahn bertujuan agar pemberi pinjaman lebih mempercayai pihak yang berutang. Pemeliharaan dan penyimpanan barang gadaian pada hakekatnya adalah kewajiban pihak yang menggadaikan (rahn), namun dapat juga dilakukan oleh pihak yang menerima barang gadai (murtahin) dan biayanya harus ditanggung rahin. Besarnya biaya ini tidak boleh ditentukan berdasarkan jumlah pinjaman.

Dalam rahn, barang gadaian tidak otomatis menjadi milik pihak yang menerima gadai (pihak yang memberi pinjaman) sebagai pengganti piutangnya. Dengan kata lain fungsi rahn di tangan murtahin (pemberi utang) hanya berfungsi sebagai jaminan utang dari rahin (orang yang berutang). Namun, barang gadaian tetap milik orang yang berutang.

\section{Skema Rahn}

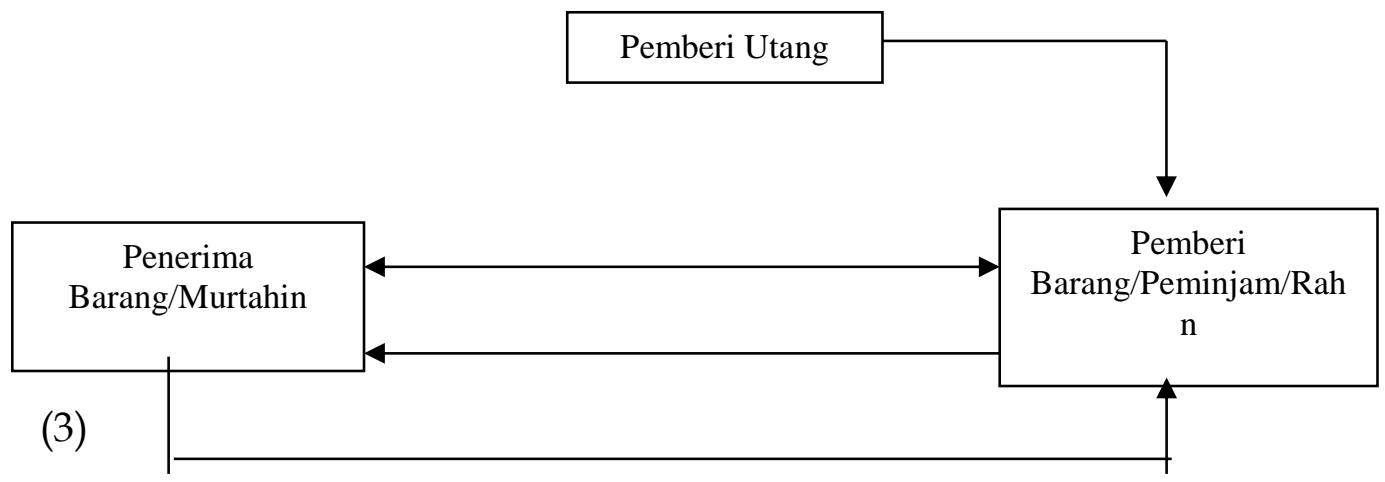

Keterangan:

(1) Pemberi pinjaman menyepakati akad rahn/rahn tajlisi dengan pinjaman

(2) Pemberi pinjaman menerima barang/surat berharga atas barang (jika fidusia)

(3) Penerima barang-barang akan mengembalikan barang yang dijaminkan ketika akad selesai (Sri Nurhayati Dan Wasilah, 2009: 256)

Sebagaimana halnya instritusi yang berlabel syariah, maka landasan hukum pegadaian Syariah juga mengacu kepada syariah Islam yang bersumber dari Al Quran dan Hadist Nabi SAW. Adapun landasan yang dipakai adalah Quran Surat Al Baqarah ayat 283; 
“Dan Jika kamu dalam perjalanan sedang kamu tidak mendapatkan seorang penulis, maka hendaklah ada barang tanggungan yang dipegang. Tetapi, jika sebagian kamu mempercayai sebagian yang lain, hendaklah yang dipercayai itu menunaikan amanatnya (hutangnya) dan hendaklah ia bertakwa kepada Allah, Tuhannya. Dan janganlah kamu menyembunyikan kesaksian, karena barangsiapa yang menyembunyikannya, sungguh, hatinya kotor (berdosa). Allah Maha Mengetahui apa yang kamu kerjakan." Hadist

1. Aisyah berkata bahwa Rasul bersabda : Rasulullah membeli makanan dari seorang yahudi dan meminjamkan kepadanya baju besi. $H R$ Bukhari dan Muslim

2. Dari Abu Hurairah r.a. Nabi SAW bersabda : Tidak terlepas kepemilikan barang gadai dari pemilik yang menggadaikannya. Ia memperoleh manfaat dan menanggung risikonya. HR Asy'Syafii, al Daraquthni dan Ibnu Majah

3. Nabi Bersabda : Tunggangan (kendaraan) yang digadaikan boleh dinaiki dengan menanggung biayanya dan bintanag ternak yang digadaikan dapat diperah susunya dengan menanggung biayanya. Bagi yang menggunakan kendaraan dan memerah susu wajib menyediakan biaya perawatan dan pemeliharaan. HR Jamaah, kecuali Muslim dan An Nasai

4. Dari Abi Hurairah r.a. Rasulullah bersabda : Apabila ada ternak digadaikan, maka punggungnya boleh dinaiki (oleh yang menerima gadai), karena ia telah mengeluarkan biaya (menjaga)nya. Apabila ternak itu digadaikan, maka air susunya yang deras boleh diminum (oleh orang yang menerima gadai) karena ia telah mengeluarkan biaya (menjaga)nya. Kepada orang yang naik dan minum, maka ia harus mengeluarkan biaya (perawatan)nya. HR Jemaah kecuali Muslim dan Nasai-Bukhari (Khaerul Umam, 2013: 358-359)

Fatwa Dewan Syariah Nasional (DSN) No. 25/DSNMUI/III/2002 yang ditetapkan pada tanggal 28 Maret 2002 oleh ketua dan sekretaris DSN tentang Rahn, menentukan bahwa pinjaman dengan menggadaikan barang sebagai barang jaminan hutang dalambentuk Rahn diperbolehkan dengan ketentuan sebagai berikut :

1. Penerima gadai (Murtahin) mempunyai hak untuk menahan barang jaminan (Marhun bih) sampai semua utang nasabah (Rahin) dilunasi.

2. Barang jaminan (Marhun bih) dan manfaatnya tetap menjadi milik nasabah (Rahin).

3. Pemeliharaan dan penyimpanan barang gadai pada dasarnya menjadi kewajiban nasabah, namun dapat dilakukan juga oleh penerima gadai, sedangkan biaya dan pemeliharaan penyimpanan tetap menjadi kewajiban nasabah. 
4. Besar biaya pemeliharaan dan penyimpanan barang gadai tidak boleh ditentukan berdasarkan jumlah pinjaman.

5. Penjualan barang gadai

a. Apabila jatuh tempo, pihak pegadaian harus memperingatkan nasabahnya untuk segera melunasi hutangnya

b. Apabila nasabah tetap tidak melunasi hutangnya, maka barang gadai dijual paksa/dieksekusi melalui lelang sesuai dengan syariah

c. Hasil penjulan barang gadai tersebut digunakan untuk melunasi hutangnya nasabah, yakni melunasi biaya pemeliharaan dan penyimpanan yang belum dibayar serta biaya penjulan

d. Kelebihan hasil penjulan barag gadai tersebut menjadi milik nasabah dan kekuarangannya menjadi kewajiban nasabah (Hendi Suhendi, 2002: 107).

\section{Tujuan dan Manfaat Pegadaian}

Sifat usaha pegadaian pada prinsipnya menyediakan pelayanan bagi kemanfaatan masyarakat umum dan sekaligus memupuk keuntungan berdasarkan prinsip pengelolaan yang baik. Oleh karena itu Perum Pegadaian bertujuan sebagai berikut :

1. Turut melaksanakan dan menunjang pelaksanaan kebijaksanaan dan program pemerintah di bidang ekonomi dan pembangunan nasional pada umumnya melalui penyaluran uang pembiayaan/pinjaman atas dasar hokum gadai.

2. Pencegahan praktik ijon, pegadaian gelap, dan pinjaman tidak wajar lainnya.

3. Pemanfaatan gadai bebas bunga pada gadai syariah memiliki efek jarring pengaman social karena masyarakat yang butuh dana mendesak tidak lagi dijerat pinjaman/pembiayaan berbasis bunga.

4. Membantu orang-orang yang membutuhkan pinjaman dengan syarat mudah.

Adapun manfaat pegadaian antara lain :

1. Bagi nasabah : tersedianya dana dengan prosedur yang relative lebih sederhana dan dalam waktu yang lebih cepat dibandingkan dengan pembiayaan/kredit perbankan. Di samping itu, nasabah juga mendapat manfaat penaksiran nilai suatu barang bergerak secara professional. Mendapatkan fasilitas penitipan barang bergerak yang aman dan dapat dipercaya.

2. Bagi perusahaan pegadaian :

a. Penghasilan yang bersumber dari sewa modal yang dibayarkan oleh peminjam dana.

b. Penghasilan yang bersumber dari ongkos yang dibayarkan oleh nasabah memperoleh jasa tertentu. Bagi bank syariah yang 
mengeluarkan produk gadai syariah dapat mendapat keuntungan dari pembebanan biaya administrasi dan biaya sewa tempat penyimpanan emas.

c. Pelaksanaan misi perum pegadaian sebagai BUMN yang bergerak di bidang pembiayaan berupa pemberian bantuan kepada masyarakat yang memerlukan dana dengan prosedur yang relative sederhana.

d. Berdasarkan PP No. 10 Tahun 1990, Laba yang diperoleh digunakan untuk:

1) Dana pembangunan semesta $(55 \%)$

2) Cadangan umum $(20 \%)$

3) Cadangan tujuan (5\%)

4) Dana sosial $(20 \%)$

\section{Rukun dan Ketentuan Syariah}

Rukun al-rahn ada empat, yaitu:

1. Pelaku, terdiri atas: pihak yang menggadaikan (rahin) dan pihak yang menerima gadai (murtahin).

2. Objek akad berupa barang yang digadaikan (marhun) dan utang (marhun bih).

3. Ijab Kabul/serah terima.

Ketentuan syariah, yaitu:

1. Pelaku, harus cakap hokum baligh

2. Objek yang digadaikan (marhun)

a. Barang gadai (marhun)

1) Dapat dijual dan nilainya seimbang

2) Harus bernilai dan dapat dimanfaatkan

3) Harus jelas dan dapat ditentukan secara spesifik

4) Tidak terkait dengan orang lain (dalam hal kepemilikan)

b. Utang (marhun bih), nilai utang harus jelas demikian juga tanggal jatuh temponya.

3. Ijab kabul, adalah pernyataan dan ekspresi saling rida/rela di antara pihak-pihak pelaku akad yang dilakukan secara verbal, tertulis, melalui korespondnsi atau menggunakan cara-cara komunikasi modern (Sri Nurhayati dan Wasilah, 258)

\section{Mekanisme Pegadaian Syariah}

Mekanisme operasional Pegadaian Syariah dapat digambarkan sebagai berikut: Melalui akad rahn, nasabah menyerahkan barang bergerak dan kemudian Pegadaian menyimpan dan merawatnya di tempat yang telah disediakan oleh Pegadaian. Akibat yang timbul dari proses penyimpanan adalah timbulnya biaya-biaya yang meliputi nilai investasi tempat penyimpanan, biaya perawatan dan keseluruhan proses kegiatannya. Atas dasar ini dibenarkan bagi Pegadaian mengenakan biaya Tawazun: Journal of Sharia Economic Law Vol. 1 No. 22018 
sewa kepada nasabah sesuai jumlah yang disepakati oleh kedua belah pihak.

Pegadaian Syariah akan memperoleh keutungan hanya dari bea sewa tempat yang dipungut bukan tambahan berupa bunga atau sewa modal yang diperhitungkan dari uang pinjaman.. Sehingga di sini dapat dikatakan proses pinjam meminjam uang hanya sebagai 'lipstick' yang akan menarik minat konsumen untuk menyimpan barangnya di Pegadaian.

\section{Akad Perjanjian Gadai}

Pada dasarnya Pegadaian Syariah berjalan di atas dua akad transaksi Syariah yaitu:

1. Akad Rahn. Rahn yang dimaksud adalah menahan harta milik si peminjam sebagai jaminan atas pinjaman yang diterimanya, pihak yang menahan memperoleh jaminan untuk mengambil kembali seluruh atau sebagian piutangnya. Dengan akad ini Pegadaian menahan barang bergerak sebagai jaminan atas utang nasabah.

2. Akad Ijarah.Yaitu akad pemindahan hak guna atas barang dan atau jasa melalui pembayaran upah sewa, tanpa diikuti dengan pemindahan kepemilikan atas barangnya sendri. Melalui akad ini dimungkinkan bagi Pegadaian untuk menarik sewa atas penyimpanan barang bergerak milik nasabah yang telah melakukan akad.

\section{METODE PENELITIAN}

Penelitian ini termasuk jenis penelitian studi literatur dengan mencari referensi teori yang relevan dengan kasus atau permasalahan yang ditemukan. Referensi teori yang diperoleh dengan jalan penelitian studi literatur dan kemudian dijadikan fondasi dasar dan alat utama untuk menganalisis data.

Jenis data yang digunakan oleh penulis dalam penelitian ini adalah data sekunder yang diperoleh dari jurnal, buku, dokumentasi dan internet. Data-data yang sudah diperoleh kemudian dianalisis dengan menggunakan metode analisis deskriptif. Metode analisis deskriptif dilakukan dengan cara mendeskripsikan fakta-fakta yang kemudian disusul dengan analisis, tidak sebatas menguraika, tetapi juga memberikan pemahaman dan pen jelasan dari permasalahan yang ditemukan.

\section{PEMBAHASAN}

\section{Aplikasi Akad Rahn dalam Lembaga Keuangan Syariah}

Dalam implementasi akad rahn di lembaga keuangan syariah ada dua jenis, yaitu akad rahn dijadikan produk turunan berupa agungan atas pembiayaan, dan kedua akad rahn sebagai produk utama, dalam bentuk gadai. 


\section{Akad Rahn sebagai Produk Turunan (Jaminan Pembiayaan)}

Harta yang diagunkan disebut al-marhûn (yang diagunkan). Harta agunan itu harus diserahterimakan oleh ar-râhin kepada al-murtahin pada saat dilangsungkan akad rahn tersebut. Dengan serah terima itu, agunan akan berada di bawah kekuasaan al-murtahin. Jika harta agunan itu termasuk harta yang bisa dipindah-pindah seperti TV dan barang elektronik, perhiasan, dan semisalnya, maka serah terimanya adalah dengan melepaskan barang agunan tersebut kepada penerima agunan (al-murtahin). Bisa juga yang diserahterimakan adalah sesuatu dari harta itu, yang menandakan berpindahnya kekuasaan atas harta itu ke tangan al-murtahin, jika harta tersebut merupakan barang tak bergerak, seperti rumah, tanah dan lain-lain.

Harta agunan itu haruslah harta yang secara syar'i boleh dan sah dijual. Karenanya tidak boleh mengagunkan khamr, patung, babi, dan sebagainya. Harta hasil curian dan gasab juga tidak boleh dijadikan agunan. Begitu pula harta yang bukan atau belum menjadi milik ar-râhin karena Rasul saw. telah melarang untuk menjual sesuatu yang bukan atau belum menjadi milik kita.

Dalam akad jual-beli kredit, barang yang dibeli dengan kredit tersebut tidak boleh dijadikan agunan. Tetapi, yang harus dijadikan agunan adalah barang lain, selain barang yang dibeli (al-mabî́) tadi.

Akad ar-rahn (agunan) merupakan tawtsîq bi ad-dayn, yaitu agar al-murtahin percaya untuk memberikan utang (pinjaman) atau bermuamalah secara tidak tunai dengan ar-râhin. Tentu saja itu dilakukan pada saat akad utang (pinjaman) atau muamalah kredit. Jika utang sudah diberikan dan muamalah kredit sudah dilakukan, baru dilakukan ar-rahn, maka tidak lagi memenuhi makna tawtsîq itu. Dengan demikian, ar-rahn dalam kondisi ini secara syar'i tidak ada maknanya lagi.

Pada masa Jahiliah, jika ar-râhin tidak bisa membayar utang (pinjaman) atau harga barang yang dikredit pada waktunya, maka barang agunan langsung menjadi milik al-murtahin. Lalu praktik Jahiliah itu dibatalkan oleh Islam. Rasul saw. bersabda:

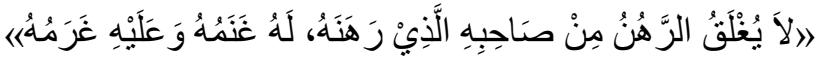

Agunan itu tidak boleh dihalangi dari pemiliknya yang telah mengagunkannya. Ia berhak atas kelebihan (manfaat)-nya dan wajib menanggung kerugian (penyusutan)-nya. (HR as-Syafii, al-Baihaqi, alHakim, Ibn Hibban dan ad-Daraquthni)

Karena itu, syariat Islam menetapkan, al-murtahin boleh menjual barang agunan dan mengambil haknya (utang atau harga kredit yang belum dibayar oleh ar-râhin) dari hasil penjualan tersebut. Lalu kelebihannya harus dikembalikan kepada pemiliknya, yakni ar-râhin. 
Sebaliknya, jika masih kurang, kekurangan itu menjadi kewajiban arrâhin. Hanya saja, Imam al-Ghazali, menegaskan bahwa hak al-murtahin untuk menjual tersebut harus dikembalikan kepada hakim, atau izin arrâhin, tidak serta-merta boleh langsung menjualnya, begitu ar-râhin gagal membayar utang pada saat jatuh temponya.

Atas dasar ini, muamalah kredit motor, mobil, rumah, barang elektronik, dsb saat ini-yang jika pembeli (debitor) tidak bisa melunasinya, lalu motor, mobil, rumah atau barang itu diambil begitu saja oleh pemberi kredit (biasanya perusahaan pembiayaan, bank atau yang lain), jelas menyalahi syariah. Muamalah yang demikian adalah batil, karenanya tidak boleh dilakukan.

\section{Pemanfaatan al-marhun oleh al-Murtahin}

Setelah serah terima, agunan berada di bawah kekuasaan almurtahin. Namun, itu bukan berarti al-murtahin boleh memanfaatkan harta agunan itu. Sebab, agunan hanyalah tawtsîq, sedangkan manfaatnya, sesuai dengan hadis di atas, tetap menjadi hak pemiliknya, yakni ar-râhin. Karena itu, ar-râhin berhak memanfaatkan tanah yang dia agunkan; ia juga berhak menyewakan barang agunan, misal menyewakan rumah atau kendaraan yang dia agunkan, baik kepada orang lain atau kepada al-murtahin, tentu dengan catatan tidak mengurangi manfaat barang yang diagunkan (al-marhun). Ia juga boleh menghibahkan manfaat barang itu, atau mengizinkan orang lain untuk memanfaatkannya, baik orang tersebut adalah al-murtahin (yang mendapatkan agunan) maupun bukan.

Hanya saja, pemanfaatan barang oleh al-murtahin tersebut hukumnya berbeda dengan orang lain. Jika akad ar-rahn itu untuk utang dalam bentuk al-qardh, yaitu utang yang harus dibayar dengan jenis dan sifat yang sama, bukan nilainya. Misalnya, pinjaman uang sebesar 50 juta rupiah, atau beras 1 ton (dengan jenis tertentu), atau kain 3 meter (dengan jenis tertentu). Pengembaliannya harus sama, yaitu 50 juta rupiah, atau 1 ton beras dan 3 meter kain dengan jenis yang sama.6 Dalam kasus utang jenis qardh ini, al-murtahin tidak boleh mamanfaatkan barang agunan sedikitpun, karena itu merupakan tambahan manfaat atas qardh. Tambahan itu termasuk riba dan hukumnya haram.

Jika ar-rahn itu untuk akad utang dalam bentuk dayn, yaitu utang barang yang tidak mempunyai padanan dan tidak bisa dicarikan padanannya, seperti hewan, kayu bakar, properti dan barang sejenis yang hanya bisa dihitung berdasarkan nilainya,8 maka al-murtahin boleh memanfaatkan barang agunan itu dengan izin dari ar-râhin. Sebab, manfaat barang agunan itu tetap menjadi milik ar-râhin. Tidak terdapat 
nash yang melarang hal itu karena tidak ada nash yang mengecualikan al-murtahin dari kebolehan itu.

Ketentuan di atas berlaku, jika pemanfaatan barang agunan itu tidak disertai dengan kompensasi. Namun, jika disertai kompensasi, seperti ar-râhin menyewakan agunan itu kepada al-murtahin, maka almurtahin boleh memanfaatkannya baik dalam akad al-qardh maupun dayn. Karena dia memanfaatkannya bukan karena statusnya sebagai agunan al-qardhu tetapi karena dia menyewanya dari ar-rahin. Dengan ketentuan, sewanya tersebut tidak dihadiahkan oleh ar-râhin kepada almurtahin. Namun, jika sewanya tersebut dihadiahkan, maka statusnya sama dengan pemanfaatan tanpa disertai kompensasi, sehingga tetap tidak boleh dalam kasus al-qardh, dan sebaliknya boleh dalam kasus dayn. (Abdurrahman dan Hafidz Abdurrahman)

\section{Keistimewaan Gadai Syariah}

1. Proses cepat, yaitu nasabah dapat memperoleh pinjaman yang diperlukan dalam waktu yang relative cepat, proses administrasi, dan penaksiran hanya 15 menit.

2. Caranya mudah, yaitu cukup dengan membawa marhun yang akan digadaikan dengan bukti kepemilikan, serta melampirkan bukti identitas. Tidak perlu membuka rekening atau cara lain yang merepotkan.

3. Jaminan keamanan atas barang, yaitu Pegadaian syariah akan memberikan jaminan keamanan atas barang yang diserahkan dengan standar keamanan yang telah teruji dan diasuransikan.

4. Pinjaman yang optimum, yaitu memberikan marhun bih hingga $90 \%$ dari nilai taksiran barang. Dengan demikian, rahin tidak dirugikan oleh rasio antara taksiran marhun dan marhun bih. Ini berarti setiap barang memiliki nilai ekonomis yang wajar.

5. Jangka waktu pinjaman, yaitu rahin atau nasabah boleh memanfaatkan pinjaman sampai jangka waktu 4 bulan.

6. Sumber pendanaan, sumber pendanaan Pegadaian Syariah berasal dari 100\% dari Bank Syariah dari Bank Muamalat Indonesia, sehingga terjamin kemurnian syariahnya (Khaerul Umam, 363-364)

\section{Perbedaan Pegadaian Syariah dengan Pegadaian Konvensional}

Pegadaian syariah tidak menekankan pada pemberian bunga dari barang yang digadaikan. Meski tanpa bunga, pegadaian syariah tetap memperoleh keuntungan, yaitu dengan cara memberlakukan biaya pemeliharaan dari barang yang digadaikan. Biaya itu dihitung dari nilai barang, bukan dari jumlah pinjaman. Sedangkan pada pegadaian konvesional, biaya yang harus dibayar sejumlah dari yang dipinjamkan. Variabel biaya pegadaian konvensional meliputi : 
1. Biaya administrasi yang ditetapkan sebesar $1 \%$ dari uang pinjaman.

2. Biaya sewa Modal yang dihitung sebagai berikut :

a. Pinjaman kurang dari Rp 20.000.000,- dengan masa pinjam setiap 15 hari sebesar $1,25 \%$.

b. Pinjaman lebih dari Rp 20.000.000,- dengan masa pinjam setiap 30 hari (1 bulan) sebesar $1 \%$.

Variabel biaya pegadaian syariah meliputi :

1. Biaya administrasi yang ditetapkan sebagai berikut :

$\operatorname{Rp} 20.000,-$ sampai dengan $\operatorname{Rp} 150.000,-\quad=\operatorname{Rp} 1.000,-$

$\operatorname{Rp} 155.000,-$ sampai dengan Rp 500.000,- $\quad=R p 3.000,-$

$\operatorname{Rp} 505.000,-$ sampai dengan $\operatorname{Rp} 1.000 .000,-\quad=R p 5.000,-$

$\operatorname{Rp} 1.050 .000,-$ sampai dengan $\operatorname{Rp} 10.000 .000,-\quad=\operatorname{Rp} 15.000,-$

Rp 10.050.000,- dan seterusnya $\quad=\operatorname{Rp} 25.000,-$

2. Biaya jasa simpanan yang dihitung sebagai berikut :

Biaya Jasa Simpanan dihitung per 10 hari, dirumuskan dengan :

Nilai Barang $x$ Tarif

Rp 10.000,-

Tarif yang dikenakan adalah :

Emas $\quad=\operatorname{Rp} 90,-$

Barang Elektronik = Rp 95,-

Motor = Rp 100,-

Jika kita bandingkan pembebanan variabel biaya-biaya tersebut, maka kita dapat perbedaan yang cukup signifikan. Misalnya barang jaminan berupa emas 22 karat seberat 60 gram dengan niai taksiran Rp 5.600.000,-. Perhitungannya adalah sebagai berikut :

\begin{tabular}{|c|c|c|}
\hline & Pegadaian Syariah & Pegadaian Konvensional \\
\hline Besar Pinjaman & $\begin{array}{l}90 \% \times \operatorname{Rp} 5,6 \text { juta }=\operatorname{Rp} 5,04 \\
\text { juta }\end{array}$ & $\begin{array}{l}89 \% \times \operatorname{Rp} 5,6 \text { juta }=R p \\
4,98 \text { juta }\end{array}$ \\
\hline $\begin{array}{l}\text { Biaya } \\
\text { Administrasi }\end{array}$ & $\operatorname{Rp} 15.000,-$ & $\begin{array}{l}1 \% \times \operatorname{Rp} 4,98 \text { juta }=\operatorname{Rp} \\
49.800,-\end{array}$ \\
\hline \multirow[t]{2}{*}{ Biaya } & $\begin{array}{l}\text { Per } 10 \text { hari: } \\
\frac{\operatorname{Rp~} 5,6 \text { juta } \times 90}{10.000,-}=\operatorname{Rp} \\
\operatorname{Rp~10.000,-}\end{array}$ & $\begin{array}{l}\text { Per } 15 \text { hari : } \\
1,25 \% \times \operatorname{Rp} 4,98 \text { juta }=\operatorname{Rp} \\
62.250,-\end{array}$ \\
\hline & $\begin{array}{l}\text { Biaya selama } 4 \text { bulan: } \\
\operatorname{Rp} 50.400,-\times 12=R p \\
604.800,-\end{array}$ & $\begin{array}{l}\text { Biaya selama } 4 \text { bulan : } \\
1,25 \% \times 8 \times \operatorname{Rp} 4,98 \text { juta }= \\
\operatorname{Rp} 498.000,-\end{array}$ \\
\hline Total Biaya & Rp 619.800,- & $\operatorname{Rp} 547.800,-$ \\
\hline
\end{tabular}

Sumber: Abdul Ghofur Ansori, Gadai Syariah, hlm. 120

Berikut disajikan tabel perbedaan teknis antara pegadaian syariah dan pegadaian konvensional : 
Studi Implementasi Akad Rahn (Gadai Syariah) Pada Lembaga Keuangan Syariah

\begin{tabular}{l|l|l}
\hline No. & Pegadaian Syariah & Pegadaian Konvensional \\
\hline 1. & $\begin{array}{l}\text { Biaya Administrasi menurut } \\
\text { ketetapan berdasarkan } \\
\text { golongan barang. }\end{array}$ & $\begin{array}{l}\text { Biaya Administrasi menurut } \\
\text { prosentase berdasarkan } \\
\text { golongan barang. }\end{array}$ \\
\hline 2. & $\begin{array}{l}\text { Jasa simpanan berdasarkan nilai } \\
\text { taksiran. }\end{array}$ & $\begin{array}{l}\text { Sewa modal berdasarkan } \\
\text { pinjaman. }\end{array}$ \\
\hline 3. & $\begin{array}{l}\text { Bila lama pengembalian } \\
\text { melebihi perjanjian, barang } \\
\text { dijual kepada masyarakat. }\end{array}$ & $\begin{array}{l}\text { Bila lama pengembalian } \\
\text { melebihi perjanjian, barang } \\
\text { dilelang kepada masyarakat. }\end{array}$ \\
\hline 4. & $\begin{array}{l}\text { Uang pinjaman 90\% dari nilai } \\
\text { taksiran. }\end{array}$ & $\begin{array}{l}\text { Uang pinjaman golongan A: } \\
\text { 90\% dari taksiran, Golongan B, } \\
\text { C, dan D : 86\% - 88\% dari nilai } \\
\text { taksiran. }\end{array}$ \\
\hline 5. & $\begin{array}{l}\text { Jasa simpanan dihitung dengan } \\
\text { konstanta X taksiran. }\end{array}$ & $\begin{array}{l}\text { Sewa modal dihitung } \\
\text { berdasarkan prosentase X uang } \\
\text { pinjaman. }\end{array}$ \\
\hline 6. & $\begin{array}{l}\text { Maksimal jangka waktu 4 } \\
\text { bulan. }\end{array}$ & $\begin{array}{l}\text { Maksimal jangka waktu 3 } \\
\text { bulan. }\end{array}$ \\
\hline 7. & $\begin{array}{l}\text { Uang kelebihan = hasil } \\
\text { penjualan - (uang pinjaman }+ \\
\text { jasa penitipan + biaya } \\
\text { penjualan) }\end{array}$ & $\begin{array}{l}\text { Uang kelebihan = hasil lelang - } \\
\text { (uang pinjaman + sewa modal + } \\
\text { biaya lelang). }\end{array}$ \\
\hline 8. & $\begin{array}{l}\text { Bila uang kelebihan dalam satu } \\
\text { tahun tidak diambil oleh } \\
\text { pemilik barang, maka } \\
\text { diserahkan kepada lembaga } \\
\text { ZIS. }\end{array}$ & $\begin{array}{l}\text { Bila uang kelebihan dalam satu } \\
\text { tahun tidak diambil oleh } \\
\text { pemilik barang, maka menjadi } \\
\text { milik pegadaian (Abdul Ghofur } \\
\text { Ansori, 2006: 120-121) }\end{array}$ \\
\hline
\end{tabular}

\section{KESIMPULAN}

Berdasarkan uraian pembahasan di atas, dapat disimpulkan bahwa Gadai merupakan salah satu kategori dari perjanjian utang piutang, yang mana untuk suatu kepercayaan dari orang yang berpiutang, maka orang yang berutang menggadaikan barangnya sebagai jaminan terhadap utangnya itu. Berdasarkan dasar hukum di atas, dapat dikatakan bahwa Gadai dalam Islam diperbolehkan dan tidak dilarang dalam Islam. Sebagai dasar hukumnya terdapat dalam Al-Qur'an, Hadits dan Ijma'.

Rahn tidak hanya digunakan dalam perusahaan umum pegadaian saja, namun juga praktik rahn ini telah diterapkan atau diaplikasikan dalam perbankan syari'ah, tetapi bukan menjadi produk utama melainkan sebagai pelengkap. Salah satu manfaat yang dapat diambil pihak bank dari praktik rahn ini adalah memberikan keamanan bagi semua penabung dan 
pemegang deposito bahwa dananya tidak akan hilang begitu saja jika nasabah peminjam ingkar janji karena ada suatu asset atau barang (marhun) jaminan yang dipegang oleh bank. Penelitian selanjutnya dapat menggunakan metode penelitian studi kasus agar hasil penelitian bisa lebih empiris.

\section{DAFTAR PUSTAKA}

Abdul Ghofur Ansori, (2006), Gadai Syariah di Indonesia : Konsep, Implementasi dan Institusionalisasi, Yogyakarta: Gadjah Mada University Press.

Hendi Suhendi, (2002), Figh Muamalah, Jakarta: Rajawali Press.

Khaerul Umam, (2013), Manajemen Perbankan Syariah, Bandung: CV Pustaka Setia.

Muhammad Firdaus, dkk, (2005), Fatwa-Fatwa Ekonomi Syariah Kontemporer, Jakarta: Renaisan, Cet 1.

Sri Nurhayati dan Wasilah, (2009), Akuntansi Syariah di Indonesia, Jakarta: Salemba Empat.

Harry Ahby, Pegadaian Syariah, diakses pada Minggu, 28 Mei 2017 pukul 21.16 WIB

Imron Al Hushein, Pegadaian Syariah, diakses pada Minggu, 28 Mei 2017 pukul 21.18 WIB

Penerapan Rahn di Perbankan Syariah, diakses pada Minggu, 28 Mei 2017 pukul 21.14 WIB

Yahya Abdurrahman dan Hafidz Abdurrahman, Rahn (Agunan) dalam Perspektif Hukum Islam 